\title{
Sampled voltammetry on an electrode array for the renewal of the electrode surface and the analytical solution during the analysis
}

\author{
Laurence Mignard $^{c}$, Matthieu Denoual ${ }^{b}$, Olivier Lavastre ${ }^{c}$, Didier Floner ${ }^{\mathrm{a}, *}$, Florence Geneste ${ }^{\mathrm{a}}$ \\ ${ }^{a}$ Université de Rennes 1, UMR-CNRS 6226, Institut des Sciences Chimiques de Rennes, Equipe MaCSE, Campus de Beaulieu, 35042 Rennes Cedex, France \\ ${ }^{\mathrm{b}}$ Groupe de Recherche en Informatique, Image, Automatique et Instrumentation de Caen (GREYC), CNRS UMR 6072 - ENSICAEN and Université de Caen Basse Normandie, \\ 6 Bd. du Maréchal Juin, 14050 Caen Cedex, France \\ ${ }^{c}$ Equipe ProCaDec, Université de Rennes 1, IETR, UMR-CNRS 6164, IETR, Campus de Beaulieu, 35042 Rennes Cedex, France
}

Keywords:

Array

Electrode renewal

Copper

Electroanalysis

DPV

\begin{abstract}
A B S T R A C T
Polarography with dropping mercury electrode has been widely used in electroanalysis. However, the method is less and less employed due to the toxicity of mercury. In this work, we have shown that it is possible to replace the dropping electrode by a working electrode array, allowing the renewal of the electrode surface and of the analytical solution during the analysis. This new concept has been demonstrated on copper analysis. Sampled current voltammetry has been carried out on an electrode array, giving rise to $I$ vs. E curves with a limiting diffusion plateau. The principle can be extended to other electroanalytical methods as exemplified here with differential pulse voltammetry. Linear calibration curves have been obtained with both methods and a limit of detection of $2 \times 10^{-5} \mathrm{~mol} \mathrm{~L}^{-1}$ has been reached for copper detection by differential pulse voltammetry.
\end{abstract}

\section{Introduction}

Polarography with dropping mercury electrode (DME) [1] has a lot of importance to the history of electroanalytical chemistry. Additionally to the very good potential window in the cathodic direction due to high overpotential of hydrogen discharge on mercury surface, an advantage of the method is the continuous renewal of the electrode during the analysis. This is particularly useful when the modification of the electrode surface occurs during the analysis of some compounds, such as metals with electrodeposition or species that adsorbed on the surface during the electrochemical analysis. Due to the high toxicity of mercury, new materials have been employed such as bismuth and boron-doped diamond, which display analytical performances comparable to mercury electrodes but are less toxic [2-5]. Whereas interesting progress have been made in materials with high potential window, the renewal of the electrode surface during the analysis of metals or species that adsorbed is still a challenge. A few papers deal with the use of Galinstan electrode as an alternative to the common dropping mercury electrodes [6,7]. This eutectic alloys mainly consisting of gallium, indium, and tin combines the advantages of a liquid state at room temperature and of a high hydrogen overpotential. However, the use of a liquid electrode can be a drawback to achieve a portable electroanalytical system allowing to approach the ideal real-time analysis.

\footnotetext{
* Corresponding author. Tel.: +33 223235010; fax: +33 223236939.

E-mail address: Didier.Floner@univ-rennes1.fr (D. Floner).
}

Electrode and more particularly microelectrode arrays have been the subject of many investigations. They have been widely used to replace a single microelectrode for improvement of signal to noise ratio since it generates higher faradic currents and avoids the use of Faraday cages $[8,9]$. Other applications deal with their use as multidetection or combinatorial platforms [10-13]. They can be produced by many techniques that give rise to a large choice of electrode materials such as platinum, gold, carbon, and boron doped diamond [14-17].

In this work, we report for the first time to our knowledge the use of an electrode array to mimic dropping mercury electrodes. Sampled current voltammetry [18] is applied on an electrode array, leading to continuous renewal of the electrode surface and of the analytical solution close to the electrode during the analysis. Since the electrode is not liquid, its surface is constant and the system can be portable. The concept is demonstrated here on copper detection, leading to good sensitivities. The method can be generalized to other voltammetry modes as illustrated with differential pulse voltammetry.

\section{Experimental section}

\subsection{Reagents and materials}

Ammonium sulfate, sodium sulfate, boric acid and copper sulfate pentahydrate were purchased from Acros. All solutions were prepared with ultra-pure water (18.2 M $\Omega$, Millipore 


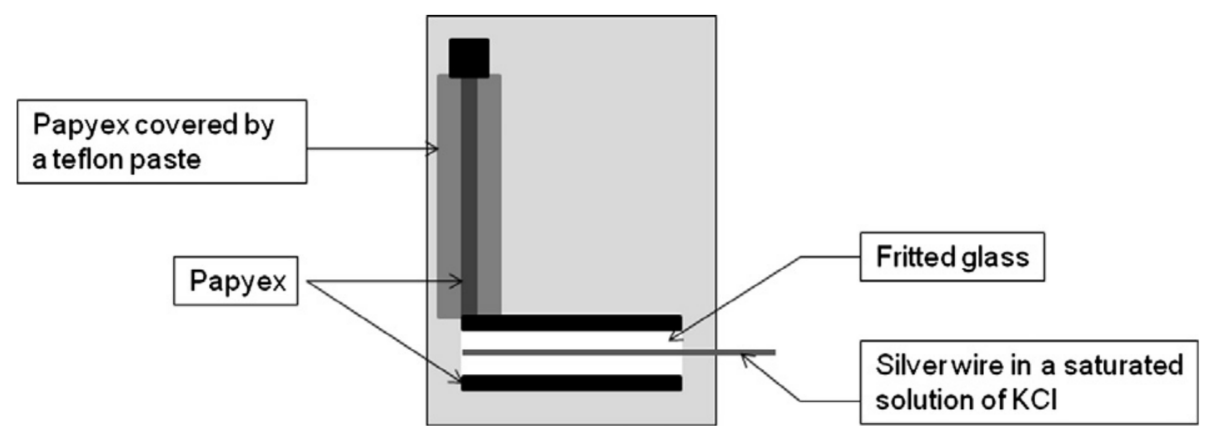

Fig. 1. Design of the counter electrode and the $\mathrm{Ag} / \mathrm{AgCl}$ reference electrode.

Simplicity). All glassware and flow reactor were rinsed with a $10 \%$ $\mathrm{HNO}_{3}$ solution followed by ultra-pure water before use to avoid metal contamination. The working electrode array was made by techniques of printed circuit boards with copper plating.

\subsection{Electrochemical measurements}

Voltammetric experiments were carried out with the use of an EDAQ potentiostat unit, with the EChem and scope software package. A vitreous carbon rotating disk electrode (Radiometer-Tacussel) as working electrode, a platinum wire auxiliary electrode, and a

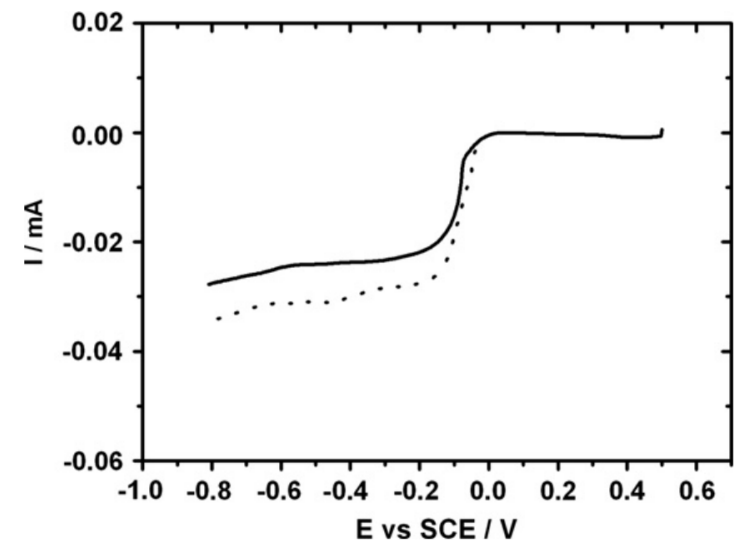

Fig. 2. Current-voltage curves of a $10^{-3} \mathrm{M}$ solution of $\mathrm{CuSO}_{4}$ in a solution of $10^{-2} \mathrm{M}$ $\left(\mathrm{NH}_{4}\right)_{2} \mathrm{SO}_{4}$ and $5 \times 10^{-2} \mathrm{M} \mathrm{Na}_{2} \mathrm{SO}_{4}$ at copper (---) and gold $(-)$ rotating disk electrodes $(1000 \mathrm{rpm})$. Scan rate: $0.01 \mathrm{~V} \mathrm{~s}^{-1}$.

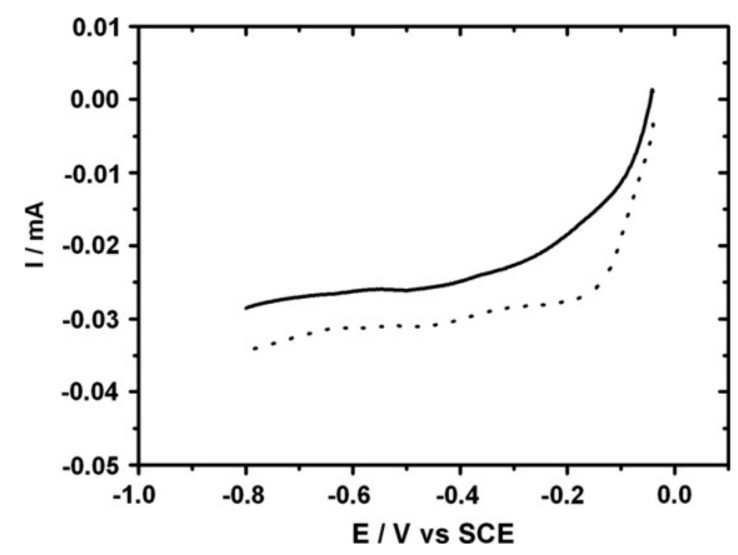

Fig. 3. Current-voltage curves of a $10^{-3} \mathrm{M}$ solution of $\mathrm{CuSO}_{4}$ in a solution of $10^{-2} \mathrm{M}$ $\mathrm{H}_{3} \mathrm{BO}_{3}$ and $5 \times 10^{-2} \mathrm{M} \mathrm{Na}_{2} \mathrm{SO}_{4}(-)$ and a solution of $10^{-2} \mathrm{M}\left(\mathrm{NH}_{4}\right)_{2} \mathrm{SO}_{4}$ and $5 \times 10^{-2} \mathrm{M} \mathrm{Na}_{2} \mathrm{SO}_{4}$ (---) at a copper rotating disk electrode (1000 rpm). Scan rate: $0.01 \mathrm{~V} \mathrm{~s}^{-1}$ saturated calomel reference electrode (SCE) were used in a standard three-electrode configuration. Voltammetric analyses were performed in a solution of $10^{-2} \mathrm{M}\left(\mathrm{NH}_{4}\right)_{2} \mathrm{SO}_{4}$ and $5 \times 10^{-2} \mathrm{M} \mathrm{Na}_{2} \mathrm{SO}_{4}$ or a solution of $10^{-2} \mathrm{M} \mathrm{H}_{3} \mathrm{BO}_{3}$ and $5 \times 10^{-2} \mathrm{M} \mathrm{Na}_{2} \mathrm{SO}_{4}$ under a dinitrogen atmosphere. The analyses with the array were performed in a flask. The counter electrode was formed by a graphite sheet (Papyex from Mersen) surrounded the reference electrode (Fig. 1).

The reference electrode was formed by a silver wirer dipped in a saturated solution of $\mathrm{KCl}$. The counter electrode and the reference electrode have the same width than the working electrode array and were placed in front of it at about $5 \mathrm{~mm}$.

\section{Results and discussion}

\subsection{Analytical conditions determined by rotating disk electrode voltammetry}

Techniques of printed circuit boards (PCBs) have been chosen for the preparation of electrode arrays since it can allow their production in a high number at relatively low cost. Since gold

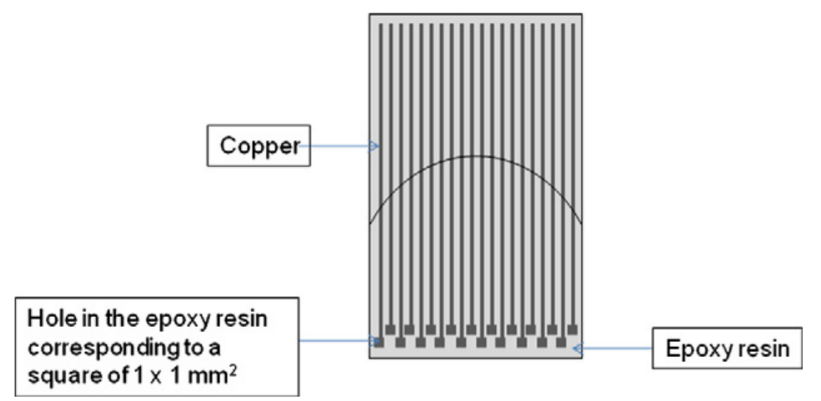

Fig. 4. Design of the electrode array composed of 20 working electrodes of $1 \mathrm{~mm}^{2}$.

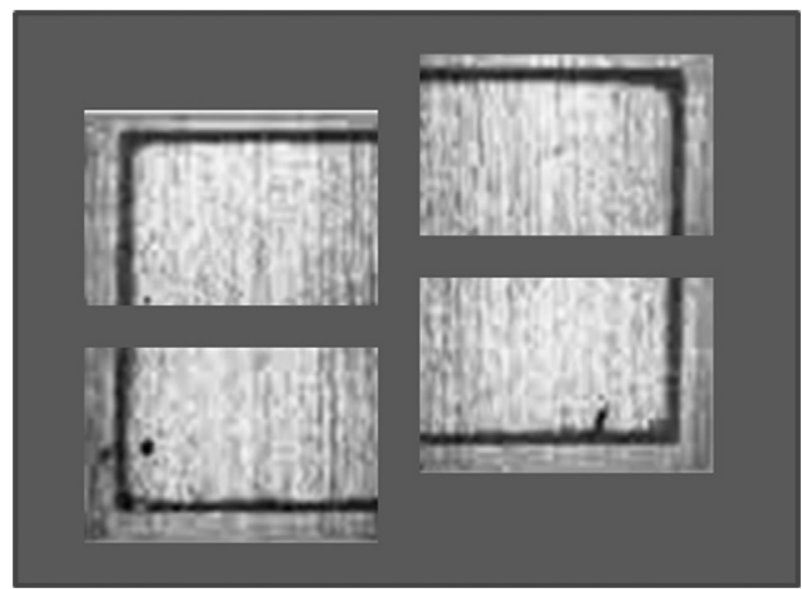

Fig. 5. Photography of the angle and the side of 4 WEs $(\times 10)$. 

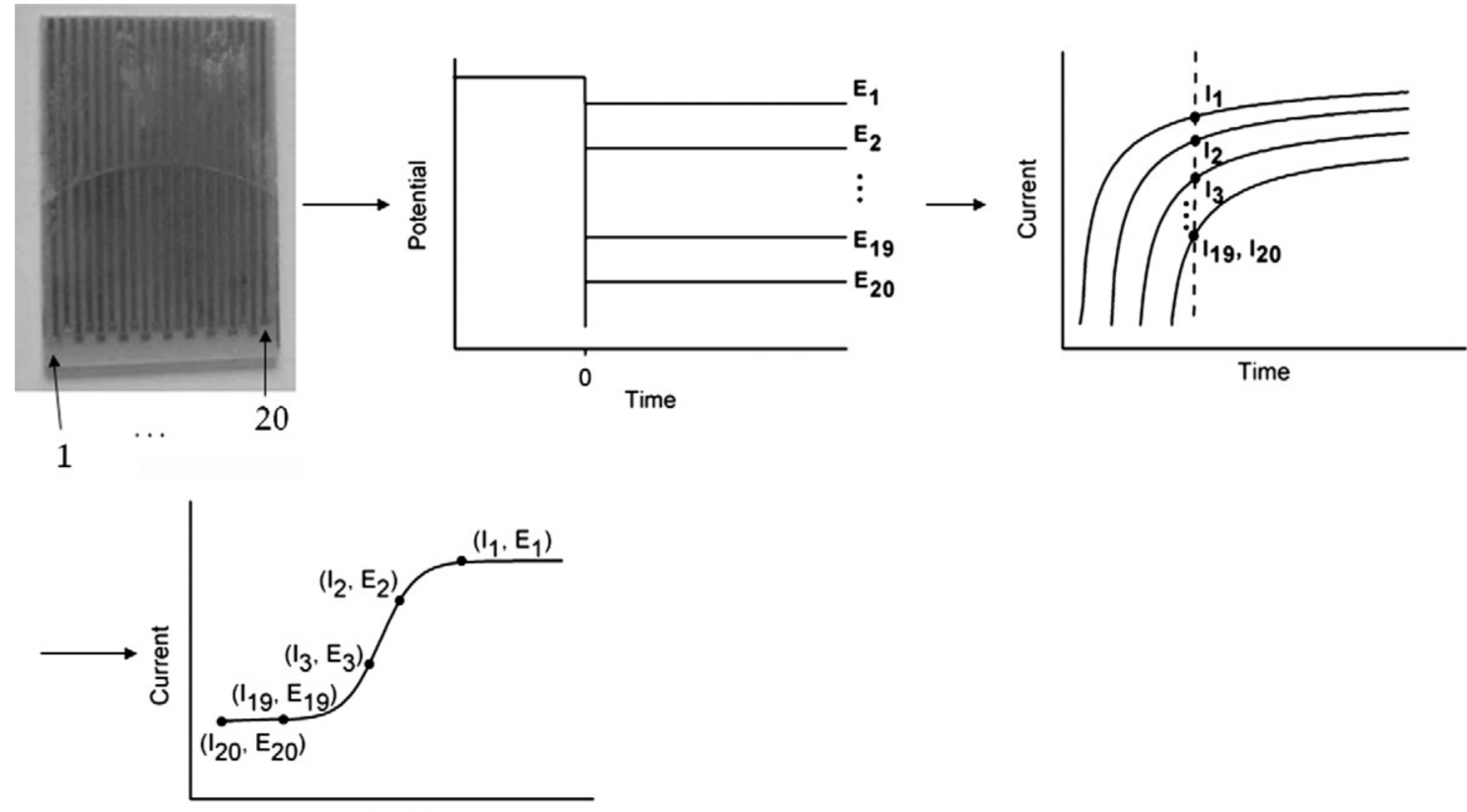

Potential

Fig. 6. Sampled-current voltammetry on an electrode array to trace the I vs. E curve.

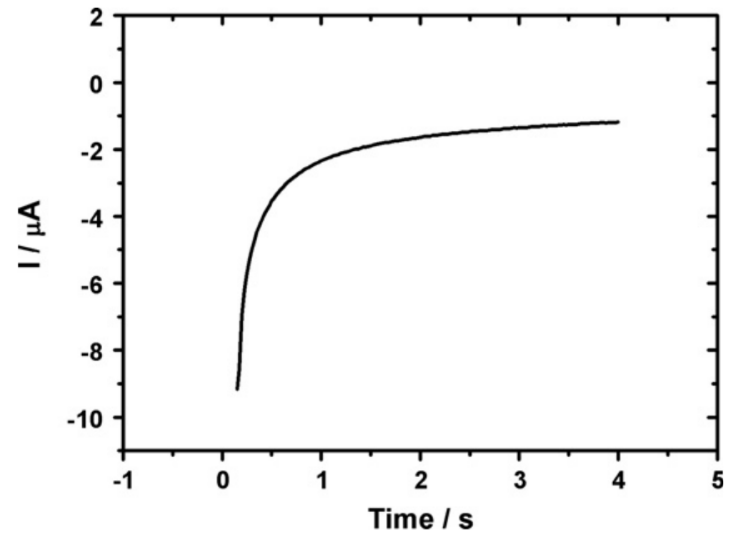

Fig. 7. Chronoamperometry at $-0.5 \mathrm{~V}_{\mathrm{Ag} / \mathrm{AgCl}}$ on a $\mathrm{WE}$ of the electrode array in a $10^{-3} \mathrm{M}$ solution of copper in a solution of $10^{-2} \mathrm{M}\left(\mathrm{NH}_{4}\right)_{2} \mathrm{SO}_{4}$ and $5 \times 10^{-2} \mathrm{M}$ $\mathrm{Na}_{2} \mathrm{SO}_{4}$.

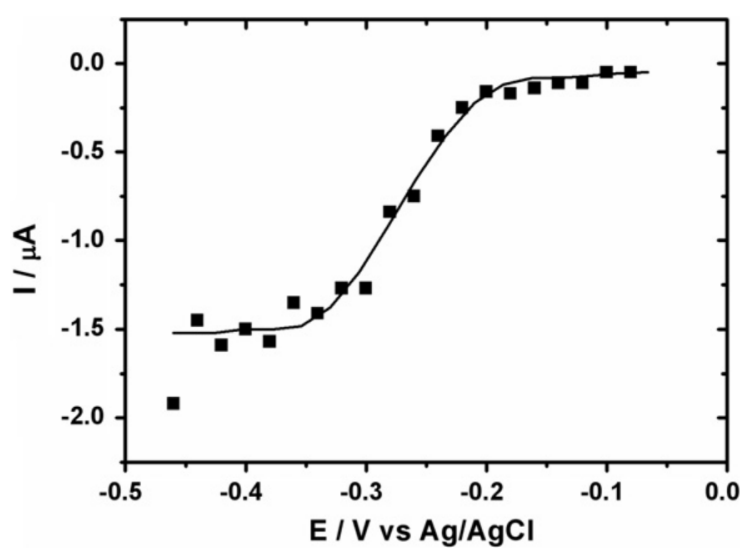

Fig. 8. I vs. E curve obtained by sampled-current voltammetry on an electrode array in a $10^{-3} \mathrm{M}$ solution of copper in a solution of $10^{-2} \mathrm{M}\left(\mathrm{NH}_{4}\right)_{2} \mathrm{SO}_{4}$ and $5 \times 10^{-2} \mathrm{M}$ $\mathrm{Na}_{2} \mathrm{SO}_{4}$. An electrolysis time of $4 \mathrm{~s}$ was used for all WEs. The potential was incremented by $0.02 \mathrm{~V}: E_{n+1}=E_{n}+0.02$.

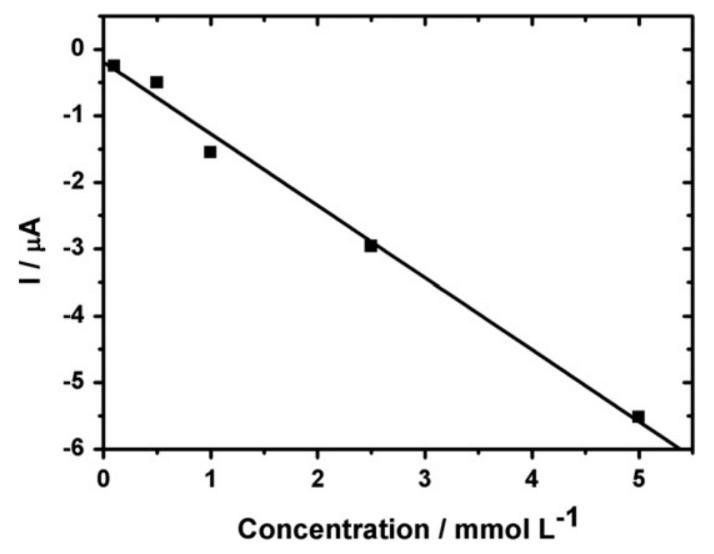

Fig. 9. Calibration curve of limiting current determined by sampled-current voltammetry analysis on an electrode array as a function of $\mathrm{Cu}^{2+}$ concentration.

and copper are common materials for plating of PCBs in the electronics industry, we first investigated the electrochemical response of $\mathrm{Cu}^{2+}$ on gold and copper electrodes in a solution of $10^{-2} \mathrm{M}$ $\left(\mathrm{NH}_{4}\right)_{2} \mathrm{SO}_{4}$ and $5 \times 10^{-2} \mathrm{M} \mathrm{Na}_{2} \mathrm{SO}_{4}$ by rotating disk electrode voltammetry (Fig. 2).

The electrochemical response corresponding to the reduction of $\mathrm{Cu}^{2+}$ into $\mathrm{Cu}^{0}$ was observed around $-0.1 \mathrm{~V}_{\mathrm{SCE}}$ on copper and gold electrodes, showing that copper electrochemical analysis can be achieved on both types of electrodes. The signal was a little bit higher (around $8 \%$ ) on copper electrodes than on gold. For this reason and since the electrode array is disposable, copper electrodes have been chosen for investigations of $\mathrm{Cu}^{2+}$ analysis on the electrode array. Different electrolyte mediums were also investigated. Since the $\mathrm{pH}$ of samples to be analyzed is usually around 7 , it is interesting to test the electrochemical response of the electrode array in neutral medium. However, for this study, the $\mathrm{pH}$ of the solution was chosen lower than 5.7 to avoid the precipitation of copper hydroxides happening for concentrations higher than $10^{-2} \mathrm{M}$ of $\mathrm{Cu}^{2+}$. Two solutions were tested: a solution of $10^{-2} \mathrm{M}\left(\mathrm{NH}_{4}\right)_{2} \mathrm{SO}_{4}$ and $5 \times 10^{-2} \mathrm{M} \mathrm{Na}_{2} \mathrm{SO}_{4}$ and another one of $10^{-2} \mathrm{M} \mathrm{H}_{3} \mathrm{BO}_{3}$ and $5 \times 10^{-2} \mathrm{M} \mathrm{Na}_{2} \mathrm{SO}_{4}$ (Fig. 3). 

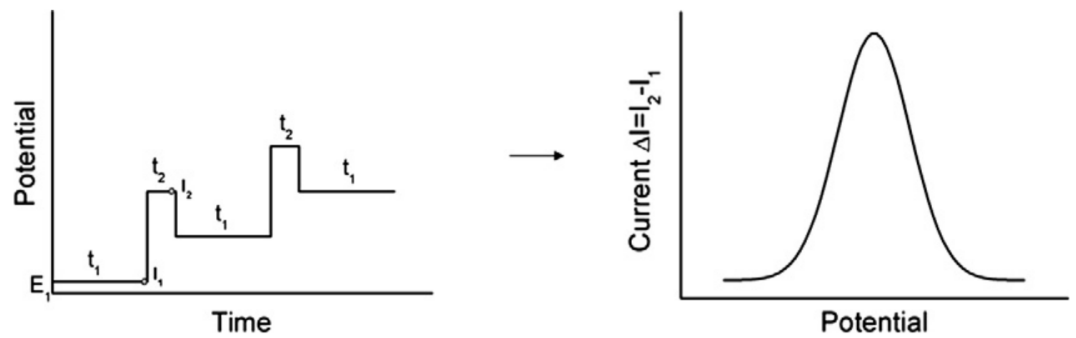

Fig. 10. Principe of differential pulse voltammetry.

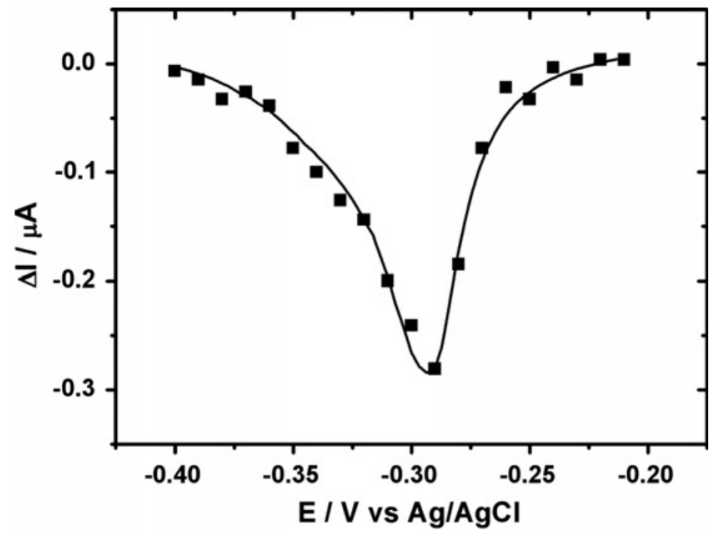

Fig. 11. Curve obtained by differential pulse voltammetry on an electrode array in a $10^{-3} \mathrm{M}$ solution of copper in a solution of $10^{-2} \mathrm{M}\left(\mathrm{NH}_{4}\right)_{2} \mathrm{SO}_{4}$ and $5 \times 10^{-2} \mathrm{M}$ $\mathrm{Na}_{2} \mathrm{SO}_{4}$. For all the WEs, after an electrolysis of $4 \mathrm{~s}$, a pulse of $-0.05 \mathrm{~V}$ was applied for $4 \mathrm{~s}$. The current was measured after 3.8 and $7.8 \mathrm{~s}$ and the difference $\Delta I$ is displayed.

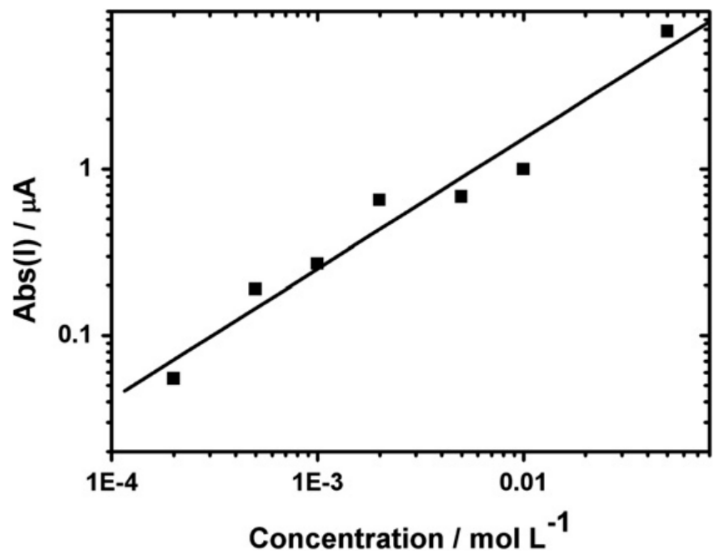

Fig. 12. Calibration curve of the absolute value of the minimum current $\Delta I$ determined by differential pulse voltammetry on an electrode array as a function of $\mathrm{Cu}^{2+}$ concentration.

The electrochemical responses were similar in both media, showing that the nature of the electrolyte does not influence the electrochemical reduction of copper. Further experiments will be performed in a solution of $10^{-2} \mathrm{M}\left(\mathrm{NH}_{4}\right)_{2} \mathrm{SO}_{4}$ and $5 \times 10^{-2} \mathrm{M}$ $\mathrm{Na}_{2} \mathrm{SO}_{4}$.

\subsection{Design of the working electrode array}

An array of copper working electrodes formed by squares of $1 \mathrm{~mm}$ side was prepared by PCBs techniques (Fig. 4).

The nature and surface area of each working electrode of the array has to be identical to trace the I vs. E curve. A film of epoxy resin was added to protect the connections, with holes formed by squares of $1 \mathrm{~mm}$ side on the copper working electrodes. The electrode array was observed by microscopy (Fig. 5).

At the scale of the photography, the squares seem to have the same surface area.

\subsection{Sampled-current voltammetry on an electrode array}

Sampled-current voltammetry was used to trace the I vs. E curve with the electrode array as explained in Fig. 6.

A potential En $(n=1-20)$ was applied on each electrode $n$ of the array. Since it was composed of 20 working electrodes, $n$ varied from 1 to 20. The value of the current response In was measured after a time $t$. The typical $I v$ s. time curve obtained is given in Fig. 7 .

The current response decreased with the time since species must diffuse to the electrode surface in order to react [18]. Different attempts were made to test the reproducibility of the electrochemical response according to the electrolysis time. Even if the current signal was higher, short electrolysis times led to low accuracy. An electrolysis time of $4 \mathrm{~s}$ was chosen in this study to assure a better reproducibility of the current signal (around 10\%) whatever the applied potential and the concentration of the solution.

The current response was read and reported to trace the I vs. E curve given in Fig. 8.

As expected with voltammetry performed with renewal of the solution closed to the electrode surface, the current decreases with the potential to reach the limiting diffusion plateau. The half-wave potential value is cathodically shifted compared with current-voltage curves at copper rotating disk electrode (Fig. 2). This result shows that the WEs of the array made by PCBs techniques were not in pure copper. The dependence of the limiting current on the $\mathrm{Cu}^{2+}$ concentration of the analyzed solution is given in Fig. 9.

The current varies linearly with the bulk concentration of the species with a correlation coefficient of 0.9962 , as described by the Cottrell equation for steady-state mass-transport controlled reaction [18].

\subsection{Differential pulse voltammetry on an electrode array}

Interestingly, other electrochemical methods can be applied to the electrode array, as illustrated in this work with differential pulse voltammetry. With this technique, the potential wave form consists of small pulses of constant amplitude superimposed upon a staircase wave form (Fig. 10).

The current is sampled before the pulse and at the end of the pulse, and the difference between these two current values is recorded. With the electrode array, each period was performed on one electrode, leading to an electrochemical response as a peak shape (Fig. 11).

Since, the height of the peak is proportional to the concentration of the bulk solution, the calibration curve is linear with a correlation coefficient of 0.9960 . The calibration curve in logarithmic scale is represented in Fig. 12. 
The limit of detection ( $3 \times$ the standard deviation of five blank determinations) was determined from the following equation [19]:

$\mathrm{St}-\mathrm{Sb} \geqslant 3 \sigma$

where St is the gross analyte signal, Sb the field blank and $\sigma$ the variability in the field blank.

By calculation from the equation of the calibration curve (for more precision in low concentration range, only the concentrations between $2 \times 10^{-4}$ and $2 \times 10^{-3}$ were considered for the calculation of the equation of the calibration curve), we calculated a limit of detection of $2 \times 10^{-5} \mathrm{~mol} \mathrm{~L}^{-1}(1.3 \mathrm{ppm})$ with $\mathrm{Sb}=0.74 \mathrm{nA}(3 \sigma=$ $0.12 \mathrm{nA}$ ).

The value is similar to the European drinking water guidelines (European communities regulation 2007, S.I. no. 278 of 2007) for copper set at $3 \times 10^{-5} \mathrm{~mol} \mathrm{~L}^{-1}(2 \mathrm{ppm})$ underlying the interest of the method for the detection of copper. It is higher than the limit of detection obtained by differential pulse polarography for copper $\left(10^{-7} \mathrm{~mol} \mathrm{~L}^{-1}[20]\right)$, which can be explained by the high affinity of mercury with metals associated to the enhancement of mass transport due to the spherical diffusion of electroactive species and the relative convective movement between the electrode and solution during drop growth.

\section{Conclusion}

In conclusion, the interest of an electrode array to perform sampled-current voltammetry is shown here with the detection of copper. Classical $I$ vs. E curves with a limiting current plateau was obtained, since the solution was renewed close to the electrode surface during the analysis. Interestingly, other methods can be applied on the array as illustrated here with differential pulse voltammetry. Calibration curves drawn by both electroanalytical techniques were linear with the concentration. The performances of the analytical method are promising since the detection limit already reached
$2 \times 10^{-5} \mathrm{~mol} \mathrm{~L}^{-1}$ for DPV. This method can be particularly useful for compounds that adsorb on the electrode surface, since passivation phenomena tend to decrease the electrochemical response.

\section{Acknowledgments}

This work was supported by the CNRS, the University of Rennes 1 , and Rennes Metropole. Dominique Paris is greatly acknowledged for his technical help in electrodes fabrication.

\section{References}

[1] J. Heyrovsky, Chem. Listy 16 (1922) 256.

[2] S.E. Ward Jones, R.G. Compton, Curr. Anal. Chem. 4 (2008) 170-176.

[3] C. Kokkinos, A. Economou, Curr. Anal. Chem. 4 (2008) 183-190.

[4] J. Wang, Electroanalysis 17 (2005) 1341-1346.

[5] R.G. Compton, J.S. Foord, F. Marken, Electroanalysis 15 (2003) 1349-1363.

[6] P. Surmann, H. Zeyat, Anal. Bioanal. Chem. 6 (2005) 1009-1013.

[7] H. Channaa, P. Surmann, Pharmazie 64 (2009) 161-165.

[8] O. Ordeig, J. del Campo, F.X. Munoz, C.E. Banks, R.G. Compton, Electroanalysis 19 (2007) 1973-1986.

[9] X.-J. Huang, A.M. O’Mahony, R.G. Compton, Small 5 (2009) 776-788.

[10] M.G. Sullivan, H. Utomo, P.J. Fagan, M.D. Ward, Anal. Chem. 71 (1999) 43694375.

[11] P. Strasser, Q. Fan, M. Devenney, W.H. Weinberg, J. Phys. Chem. B 107 (2003) 11013-11021.

[12] R. Polsky, J.C. Harper, D.R. Wheeler, S.M. Brozik, Electroanalysis 20 (2007) 671679.

[13] J. Wu, Y. Yan, F. Yan, H. Ju, Anal. Chem. 80 (2008) 6072-6077.

[14] C.-Y. Lee, Y.-J. Tan, A.M. Bond, Anal. Chem. 80 (2008) 3873-3881.

[15] L. Xiao, I. Streeter, G.G. Wildgoose, R.G. Compton, Sens. Actuator B 133 (2008) 118-127.

[16] E.M. Richter, R.A.A. Munoz, M. Bertotti, L. Angnes, Electrochem. Commun. 9 (2007) 1091-1096.

[17] A. Uhlig, U. Schnakenberg, R. Hintsche, Electroanalysis 9 (1997) 125-129.

[18] A.J. Bard, L.R. Faulkner, Electrochemical Methods: Fundamentals and Applications, second ed., John Wiley \& Sons, New York, 2001.

[19] D. MacDougall, W.B. Crummett, et al., Anal. Chem. 52 (1980) 2242-2249.

[20] A.M. Bond, D.R. Canterford, Anal. Chem. 44 (1972) 721-731. 